This is the peer reviewed version of the following article: McCarroll, Clare, van't Riet, Catherine and Halter, Mary (2020) How is the emerging role of domiciliary physiotherapists who treat residents with dementia in nursing homes perceived by allied health professionals? A phenomenological interview study. Health \& Social Care in the Community, 28(1), pp. 279-290., which has been published in final form at https://doi.org/10.1111/hsc.12862. This article may be used for non-commercial purposes in accordance with Wiley Terms and Conditions for Use of Self-Archived Versions. 


\section{How is the emerging role of domiciliary physiotherapists who treat residents with dementia in nursing homes perceived by allied health professionals? A phenomenological interview study}

\section{Abstract}

Dementia affects the majority of older residents in nursing homes and physiotherapists are regularly involved with this population. However, little is known about the role of physiotherapists who treat residents with dementia in nursing homes. The aim of this paper was to report on an interpretivist qualitative exploration of the perceptions of both the providers of and referrers to domiciliary physiotherapy for residents with dementia in nursing homes in London. In 2015, we conducted semi structured interviews with ten purposively sampled participants - two were providers of physiotherapy for residents with dementia in nursing homes, five were referrers to these providers, and three occupied dual roles. A thematic analysis of the verbatim transcripts identified three main themes. First were perceptions of a multifaceted but unclear role, focused on both conventional 'physical' physiotherapy interventions and specialist care, the latter being reliant on knowledge and confidence that physiotherapists did not always feel they possessed. Second were the stated challenges to the role, including the focus and organisation of the nursing home setting, with perceived lack of emphasis on rehabilitation; the progressive and demanding nature of dementia itself; a lack of continuity of nursing home and visiting health professional staff with associated need to entrust physiotherapy intervention to multiple others; and the final challenge was the difficulty measuring impact. Third, despite the challenges, enablers of the role were experienced, namely collaborative working and positive previous experiences of referrers. Joining these themes were underpinning concepts of complexity and uncertainty in relation to the physiotherapy role in this setting. This paper highlights a need for enhanced collaborative working in clinical practice, enabled at organisational level, to help address some of the uncertainties expressed around the physiotherapists' role with residents with dementia in nursing homes and thereby enable improvements to processes and outcomes of their interventions.

\section{Key words}

Dementia, physiotherapists, Physical Therapists, Nursing Homes, Role 


\section{What is known about this topic}

- The majority of residents of nursing homes are affected by dementia

- Physiotherapy has a role in addressing the cognitive, emotional and physical impacts of dementia

- Studies have explored the perceptions of physiotherapy with people with both dementia and hip fracture, but none have explored this in nursing homes.

\section{What this paper adds}

- Understanding of the complexity and uncertainty underpinning and restricting the impact of the role of physiotherapy with residents with dementia in nursing homes

- The voice of the professionals involved in setting out the enablers for achieving an improvement

- The need for further research, including residents and their families and other health care providers. 


\section{How is the emerging role of domiciliary physiotherapists who treat residents with dementia in nursing homes perceived by allied health professionals? A phenomenological interview study}

\section{Main text}

\section{Background}

An estimated 46.8 million people worldwide (Prince, 2015) and approximately 850,000 people in the United Kingdom (UK) alone (Alzheimer's Society, 2014) live with dementia. Dementia can result in physical and emotional difficulties impacting on an individual's ability to participate in functional activities (Barrett \& Burns, 2014). Sustaining independence and improving quality of life for people with dementia is one of the National Health Service (NHS) outcomes measures (Department of Health, (DOH), 2016). However, loss of function can result in transitioning into a nursing home setting (DOH 2011) where it is estimated that $73 \%$ of people have dementia (Alzheimer's Society, 2014).

Physiotherapy is a dynamic health care profession concerned with maximising individuals' movement and functional abilities which can influence health and well-being across their life-cycle (Chartered Society of Physiotherapy (CSP) 2011, CSP, 2013, World Confederation for Physical Therapy (WCPT), 2015). The cognitive, gait, balance and postural control impediments associated with dementia suggest a role for physiotherapy (Hall, 2018), which has been identified as a service that can support the physical and mental health and well-being of people with dementia (National Institute for Health and Care Excellence (NICE), 2013, Scottish Intercollegiate Guidelines Network (SIGN), 2006). Although guidelines are available for health and social care professionals who treat people with dementia, none are specifically for physiotherapists. Recent, qualitative evidence from the UK suggests that challenges exist to providing physiotherapy to people with dementia following hip fracture (Hall, 2017, Hall, 2018). This includes a lack of knowledge and resource limitations, from the physiotherapist's viewpoint (Hall, 2017) and difficulties obtaining and receiving ongoing physiotherapy, from the viewpoint of people with dementia or their carers $($ Hall, 2018). In terms of physiotherapy intervention, a systematic review cautiously suggested that exercise programmes might improve the performance of activities of daily living in older people with dementia, although the impact of the setting, particularly nursing homes, was proposed as an important factor for further investigation (Forbes, 2015). Professionals working with people with dementia in care homes are anticipated to require additional skills, including 
adopting a person-centred approach, multidisciplinary collaboration and creating a meaningful and stimulating environment (NICE, 2013, DoH, 2011, SIGN, 2006, ADI, 2013, Owen \& Meyer, 2012). However, physiotherapists have reported difficulties when treating residents with dementia in the later stages of the disease, including stress and fatigue (Staples \& Killian, 2012a), negative attitudes (Staples \& Killian 2012b), poor communication with nursing home staff and a lack of clinician competence (Buddingh et al., 2013). Additionally, care home staff in the UK highlight challenges in accessing variable community health service provision (Care Quality Commission, 2014; Sackley, 2009; O'Dea, 2000; McArthur, 2015), in part due to reported lack of clarity about and knowledge of available services (Greenwood, 2014). Physiotherapists are reported to be underutilised in the care of nursing home residents with cognitive impairment (Leemrijse et al., 2007). In this context we aimed to explore perceptions of the role of domiciliary physiotherapists who treat residents with dementia in nursing homes from the viewpoint of the main referrers to, and the providers of domiciliary physiotherapy operating within multidisciplinary allied health professional (AHP) teams (Figure 1). Given that the physiotherapist's role identity appears to be context dependent (Hammond, 2016), our a priori assumption was that perceptions of the role are associated with referrer and provider behaviour.

\section{Methods}

\section{Design}

We conducted an exploratory descriptive qualitative study (Sandelowski, 2000), taking a phenomenological approach to focus on the meaning and experience of individuals within their social world (Fossey, 2002), here physiotherapy in nursing homes, using an interpretivist framework (Creswell, 2013).

\section{Data Collection Methods}

We collected data through eight semi-structured interviews, meeting participants' preferences to maximise recruitment (Williams, 2011), and facilitating in-depth explorations of individual perceptions and beliefs (Green \& Thorogood, 2014). We took a semi structured approach to ensure key questions were asked in the same way whilst also having flexibility to adjust questions, pursue interesting responses and explore participants' perceptions (Robson, 2002). We constructed the topic guide, drawing on the literature, clinical knowledge of the research team, discussion with nursing home and therapy team managers and from patient and public involvement (PPI) (feedback from carers of people with 
dementia). The PPI group suggested development of a recruitment poster, flexibility in data collection methods, and alternative questions and phraseology in the topic guide. These recommendations were incorporated into the studydesign. Reflexivity (Finlay, 2003) was maintained through the researcher keeping field notes focusing on the conduct and content of the data collection and thoughts about connections in data across data collection episodes. A reflective diary was recorded which particularly focussed on the potential influence of her professional background as a domiciliary physiotherapist and of knowing some participants from her previous clinical role.

\section{Data collection procedures}

We carried out the study in one English metropolitan local authority area with twelve nursing homes operating in its jurisdiction at the time of the study. Medical support to the nursing homes was provided by nine general practices. Domiciliary physiotherapy services were available as what we will refer to as English National Health Service (NHS) "in reach services", that is where physiotherapy was delivered as one element of a multidisciplinary domiciliary rehabilitation service (generic domiciliary therapy [see Figure 1]), provided in response to a referral, at the place of residence.

Our purposive sample (Bryman, 2012) consisted of individuals meeting our inclusion criteria (Table 1). This was developed through discussions with therapy leaders and a review of the database of nursing home referrals to local multidisciplinary domiciliary therapy teams. The "Generic" Domiciliary Therapy team received the highest proportions of referrals for nursing home residents and were identified as the "main" providers of physiotherapy. However during interviews participants from the other teams (physiotherapists and others) often reflected on their own experiences of providing therapy within their specialities to nursing home residents and hence self identified as both providers and referrers.

In the context of limited consensus around the appropriate sample size for qualitative studies (Green \& Thorogood, 2014) we aimed for up to 15 interviews, consistent with other studies exploring professionals' perceptions of physiotherapists' role in other settings (Parkes \& Ali, 2013; Goodwin, 2014).

We invited potential participants via gatekeepers. Managers of teams meeting the inclusion criteria were asked by email to forward an invitation to participate in the study to their staff members and to display posters advertising the study in communal staff areas. Hard copies of the invitation pack were delivered to nursing homes and general practices. 
We collected data in the summer of 2015 with all those who gave written informed consent.

Analysis procedures

All interviews were digitally audio-recorded and transcribed verbatim by the researcher, applying pseudonyms where necessary. To facilitate the iterative process of moving between data collection, analysis, comparisons with the literature, and thoughts of the researcher we analysed inductively using thematic analysis (Braun \& Clarke, 2006). We achieved familiarity with the data and generated initial codes and later iterations through repeated reading and comparison of independent coding between authors $(\mathrm{CMcC}, \mathrm{MH})$. We generated themes and subthemes and selected verbatim quotes in further discussion $(\mathrm{CMcC}, \mathrm{MH}, \mathrm{CvT})$. We present confirming and disconfirming cases (Yardley, 2008).

Ethical approval

Ethical approval for research involving NHS staff was granted from the lead University's Research Ethics Committee. We obtained research governance approval from the NHS organisation study site.

\section{Findings}

We recruited ten participants from domiciliary and inpatient therapy settings; all were allied health professionals with more than six years clinical experience. No GP or nursing home staff members were recruited. Table 2 describes the participants. 
Three main themes were induced from participants' data in relation to the perception of the generic domiciliary physiotherapy role. Participants described a multifaceted but unclear role where reasons for referral to physiotherapy were multiple and complex; challenges to the role such as the nursing home setting, dementia, the nature of in-reach physiotherapy, unclear referrals and measurement issues; and enablers of the role - collaborative working and positive previous experiences of referrers. We present each in turn, and illustrate their inter-relationship through the underpinning concepts of complexity and uncertainty in Figure 2.

A multifaceted role for the physiotherapist with nursing home residents with dementia

In describing the physiotherapists' role when treating people with dementia in nursing homes as multifaceted, three sub themes emerged: conventional role, specialist aspects, and a lack of clarity about, or a blurred role.

Most participants described physiotherapists as taking a 'conventional' role, focusing on physical interventions such as positioning, exercise programmes, mobility and reviewing patients' transfers, with the aim of prevention of contractures or chest infections, or ameliorating conditions by increasing comfort:

"If they're weak you give them strengthening exercises, (...), mobility practice, gait re-education, balance exercises" (P7, Physiotherapist, provider [generic domiciliary])

Additionally, the majority of participants described a need to develop more targeted and specific skills and knowledge to enable their work with people with dementia in nursing homes, this constituting a more specialist role.

"I mean the more one knows, the more specialist one can be working with dementia, the more value we would have” (P8, Physiotherapist, referrer [rehabilitation hospital])

Integral to these accounts were the concepts of adopting an individualised approach, adjusting for the resident with dementia, managing residents' mood and behaviour and aiming to maximise a resident's function and independence:

"So yeah it's around finding out what's meaningful for that person (..) and that's a lot around finding out about their life history (..), their interests, likes, dislikes (..), what personally is going to make them tick, what they want to be involved in" (P5, Physiotherapist, referrer and provider [specialist domiciliary 1])

This specialist role was described as focusing on issues supporting the delivery of physiotherapy to the person with dementia such as, addressing environmental issues and delivering patient and family disease-specific education. Although consensus was not achieved about whether or not education and training of nursing home staff was the domain of the physiotherapist: 
"I don't know whether I see that as our role if we've not done anything that's physio related (...). But is that advice just common sense? Do I need to go to university to do a physio degree to give that advice?" (P7, Physiotherapist, provider [generic domiciliary])

"we need to share our skills, so we need to empower the working population in social care.....we have this ridiculous situation where a physio might go in an hour a week and then the other, however many I have lost count 150 hours a week the carers are with them, so you know when you talk about it like that it's ludicrous isn't it, we have got to skill up the day and the night staff." (P10, Physiotherapist, referrer and provider, [specialist domiciliary 1]

"You can think of it like a jigsaw puzzle with some pieces missing. (..) at the end of the day it's going to be the care home staff who are going to be there to ......fill in those missing pieces" (P5, Physiotherapist, referrer and provider, [specialist domiciliary 1]

In addition to the issue of reluctance, a small number of participants were doubtful that physiotherapists had the confidence, experience or education to support or hone dementia specialist skills. They queried the impact of specialism on task boundaries between physiotherapists' and others' roles in the health and care team, mostly describing discomfort with the idea of blurring professional roles:

"It's very difficult I just find it quite difficult knowing where we do fit" (P9, Physiotherapist, provider [generic domiciliary]).

In contrast, one participant felt role blurring improved working practices and knowledge:

"OTs [Occupational Therapists] have learned from the physios and that's enhanced their practice and the physios [physiotherapists] have learned from the OTs [Occupational Therapists] and when we are, (..) skilled up in both areas that makes us better" (P10, Physiotherapist, referrer and provider [specialist domiciliary 1])

In the context of this multifaceted role a number of challenges were described: the nursing home setting, a lack of consistent staff, the impact of dementia itself, unclear referrals and expectation of outcome.

Challenges to the physiotherapists' role with nursing home residents with dementia

Most participants emphasised that what they described as 'the nursing home culture' was perceived to be the main barrier to the physiotherapists' role; the nursing home environment was depicted as activity-limiting, which participants suggested could oppose the aim of the conventional physiotherapy role around promoting mobility: 
"It's a very medical model as well (..) and our training is so much more holistic now, (..) so it's just a bit of a clash of cultures (P5, Physiotherapist, referrer and provider [specialist domiciliary 1])

Some participants offered understanding of the priorities for nursing home staff in terms of delivering residents' safety and fundamental care needs such as eating, warmth, and toileting over promoting activity. However, in this context, most physiotherapy participants felt disempowered in terms of what they could influence, when they perceived that organisational level change was required:

"unless the environment changes, no matter how mobile we get patient A.....or how strong we get them, if there's not appropriate signage and ..... if there's a patterned carpet and she is scared to walk on it because of the perceptual problems ..... in some ways you could say what's the point in a physio going in and that is my feeling" (P10, Physiotherapist, referrer and provider [specialist domiciliary 1])

Concerns expressed with the setting included a lack of continuity of nursing home staff, considered by most to impact negatively on gaining support and sharing information. Conversely, one participant (P10) felt that physiotherapists could address this perceived barrier by broadening their ideas and by being flexible within the nursing home; reflecting challenges highlighted earlier around role blurring. However, the absence of consistent physiotherapy staff within the nursing home and lack of time were presented as barriers to developing good links with nursing home staff:

"If we did have a bit more, more time you know (..) you know we might be more successful" (P1, Occupational Therapist, a referrer on the main provider team [generic domiciliary]).

In terms of the dementia itself, several participants described an increasing public and NHS profile regarding dementia and suggested this may influence practices positively. However, they also highlighted features of the diagnosis and nature of dementia that they considered had a negative impact on the physiotherapy role. Some felt the progressing and fluctuating nature of the disease meant that referrer's expectations from physiotherapy needed to be adjusted, but that physiotherapy could offer benefit to the resident.

"it might not be with your treatment that you're expecting 100\% improvement. So you need to kind of know (the diagnosis) i.e. where are you setting your goal and how are you gonna get there" (P4, Physiotherapist, referrer and provider [specialist domiciliary 1])

Others expressed uncertainty around any anticipated impact with this population, emphasising residents' engagement with physiotherapy as being crucial to the outcome of intervention. Personal frustration, deflation and disappointment 
when working with residents with dementia were expressed. System issues, such as stigmatisation of dementia were considered to impact on the role, with reduced services and respect perceived, in comparison to the standards and clarity available for physiotherapists treating other neurological conditions:

"I think services are better set up and more defined..... particularly for MND [motor neurone disease], emm than they are for dementia" (P2, Speech and Language Therapist, referrer [specialist domiciliary 2])

In this context, participants also described inappropriate or unclear referrals as challenges to physiotherapists' role. This included a perception that referrers, especially GPs and nursing home staff, lacked understanding of and clarity about the role and their expectations of physiotherapy. This was described as impacting both negatively on the amount that physiotherapists might achieve and leading to apprehension amongst therapists:

"It seems to be we get the patients referred to us generally when they're in bed, contracted... when, there's not a lot that we can do about them physically,.... whereas it would be best to get them earlier than that" (P3, Occupational Therapist, a referrer on the main provider team [generic domiciliary]).

The apparent lack of clarity about the physiotherapist's role in working with people with dementia appeared to be reflected in participants' difficulties in identifying meaningful outcomes for this population. Many considered that the current outcome measures, conventional physical measures such as falls, independence and function were ill-suited to the resident group. Participants were looking for measures related to what they described earlier as their more specialist role working with people with dementia, emphasising impact on, for example, behaviour or participation:

"So it's around quality of life, so something where the a patient or carer perceives you're maintaining their quality of life" (P6, Speech and Language Therapist, referrer [hospital rehabilitation])

However, a few participants discussed challenges arising from what they perceived to be poor outcomes from physiotherapy, for example negatively impacting on a resident's behaviour or mood, or perhaps making no change, the latter described as letting down or not being able to meet the expectations of referrers, of the patient or their families:

"you kind of just have one of those moments where you are like oh my goodness this is really, really difficult; this is a horrible thing that the family and the patient are going through and it's quite hard for, well it is for me, to see someone like that and actually I can't help and I'm sorry I can't help; that can be quite difficult." (P9, Physiotherapist, provider [generic domiciliary])

While the physiotherapy role might be considered to be enabled by removing the challenges, participants described two potential enablers of physiotherapy: collaborative working and positive previous experiences of referrers. 
Enablers of the physiotherapists' role with nursing home residents with dementia

The majority of participants described their sense that physiotherapy was making a difference in some way to the resident with dementia, their carers or family as a positive outcome:

"doing something better than they were before" (P6, Speech and Language Therapist, referrer [specialist domiciliary 2]).

Participants who reported positive clinical experiences of physiotherapy in dementia appeared to base their perception of the value of the role on those personal encounters. A few participants talked about how they would refer to physiotherapy if it would support their own role and would use guidelines, such as those provided by professional membership or regulatory bodies to inform referrals. Gaining multidisciplinary support through joint working was seen as central to the success of the physiotherapy role with residents with dementia:

"if there was a bit more case management with people joining in together, meeting face to face(..) for the more complex patients (...) meeting in a nursing home(..), talk about complex patients between different practitioners, the outcomes (for patients) would be a lot better and maybe respect, rapport, relationship building would be better (...) but it doesn't happen" (P9, Physiotherapist, provider [generic domiciliary])

One participant reflected a broad view of the role; they discussed the need for a whole systems approach and described measures beyond their direct influence to evaluate the physiotherapists' effectiveness, including number of callouts to the ambulance service.

Family members were seen as key to: supporting residents, delivering physiotherapy interventions and recognising if and when further physiotherapy input may be needed, :

"We have to work with our other colleagues and our other carers and our relatives because otherwise the individual just doesn't remember" (P8, Physiotherapist, referrer and provider [rehabilitation hospital])

Underpinning concepts: complexity and uncertainty

The themes presented highlight that participants described the physiotherapy role in residents with dementia in nursing homes as multifaceted, requiring the use of their conventional focus as well as the acquisition and development of specialist knowledge and skills. Physiotherapists were operating in complex systems due to professional and cultural 
issues and differing priorities between individuals and the organisations. These layers of complexity fed into the uncertainty participants described related to the sometimes blurred role of the physiotherapist, to expectations from referrers and to feelings of apprehension or frustration within the role. In this complex and uncertain context, the expectation for physiotherapists to deliver a meaningful service to these residents was reported as problematic.

P5: I don't know if other people might share that it's, it's like P4 was saying there's a lot of sort of unknowns P4: $\mathrm{Mmm}$

P5: And there's a lot more complexity and a lot more challenges (P4 and P5, Physiotherapists, referrers and providers [specialist domiciliary 1]) 


\section{Summary of key findings}

The allied health professional providers of and referrers to domiciliary physiotherapy for people with dementia living in nursing homes presented us with perceptions of a multifaceted but unclear role with challenges and enablers, underpinned by complexity and uncertainty. We did not succeed in gaining the perspectives of general practitioners, acute hospital therapists and nursing home staff. Both conventional, physical-activity-related and dementia-specific, person-centred aspects of physiotherapy formed the role, the dementia-specific element presented some blurring of the physiotherapy with other health and care roles. Barriers to the role were described as the nursing home culture, dementia itself, discontinuity of nursing home and physiotherapy staff, referrals considered to be unclear, alongside confusion about the potential impact of physiotherapy. Participants did not consider the environment to be conducive to improvements and described feeling powerless to influence practice. The role was considered to be enabled by collaborative working and referrers' previous positive experiences. The overarching view was one of complexity and uncertainty - a sense of a need for the role but unclear responsibilities and boundaries, with resultant issues for both providers and referrers. Some participants, due to the multiplicity of teams involved and their prior experience, described holding referrer and provider roles simultaneously. The difficulty in defining participants as either a referrer or provider reflected perceptions of their reality of the emerging role.

Placing our findings in the context of the literature

Our finding that a conventional - mobility-based - role for physiotherapists working with residents with dementia in nursing homes continues to be prioritised was unsurprising given the body of evidence focusing on physical interventions in people with dementia in domiciliary settings (Burton, 2015; Forbes, 2015). Similar roles for physiotherapists have been described in hospitals and residential care (Stewart, 2009; Dalley, 2001; Lefmann, 2014), although Hall (2016) considered that the literature on physiotherapy in people with dementia (following hip fracture) lacks detail, with 'physiotherapy' assumed to be a treatment in itself rather than a term encompassing multiple treatment techniques. Given the literature suggesting negative attitudes or fear of physiotherapists about treating residents with dementia (Staples \& Killian, 2012b; Hall, 2017), an encouraging finding in our study was the positive attitude towards the need for individualised care and the specialist role reported amongst most participants. In common with literature regarding other neuro-degenerative conditions, there appears to be an impetus for health professionals (While et al., 2009; Keus et al., 2014) to adopt a specialist role, which includes enhanced understanding 
about the disease. The expectations of a physiotherapy dementia-specialist role could be supported by professional guidance, such as that for Parkinson Disease (Keus et al, 2014). Such guidance was lacking at the time of the study.

Role blurring was both apparent and contentious amongst participants. This tension is reflected in the literature investigating perceptions of physiotherapy roles in hospitals (Goodwin, 2014; Leffman \& Sheppard, 2014) and domiciliary settings (Smith \& Roberts, 2005) and reflects broader debates on professional roles such as professional tribalism hindering collaborative working (Smith \& Roberts, 2005). Role blurring in our study appeared to relate to uncertainty around whose role particular activities belonged to when they could be provided by several members of the health and care team.

Our finding of barriers and enablers to providing consistent, continuing, effective physiotherapy to people with dementia in nursing homes is reflected in commentary articles suggesting a challenging but successful role for physiotherapy in such settings (Lyall, 2008;CSP, 2011; Santos, 2015). Hall (2017) found people with dementia were described as 'written off'. While our participants did not suggest they held this view, they suggested that residents with dementia and visiting health professionals were negatively impacted by such constraints. Other studies report care needs being prioritised over potentially empowering physiotherapy interventions (Stewart et al., 2009). Previous studies reportingperceived barriers to physiotherapy interventions were reflected in our data, including altered expectations (Staples \& Killian, 2012b), reduced patient motivation (You et al., 2011) as well as cognitive, emotional (Buddingh et al., 2013) and behavioural difficulties (Baert et al., 2015). Participants in this study and those in closely related studies highlighted a need for clarity of the physiotherapist's role through education (Goodwin, 2014) and clearer communication around the availability and nature of services (Burn, May, Edwards, 2014; Greenwood, 2014). Furthermore, role specifications and access to dementia expertise have been identified as essential for NHS workers and care home staff to deliver appropriate care to residents in nursing homes (Goodman et al., 2017).

Collaborative multidisciplinary working practices are often reported as ideal rather than reality (Waldron et al., 2011; Smith \& Roberts, 2005), despite joint working and skill sharing being highlighted by participants and professionals within this and other studies as ways of managing barriers to rehabilitation (Dalley \& Sim, 2001) and to organising and delivering healthcare for people with dementia (Bunn et al, 2017). Since the completion of this study a growing body of literature has highlighted a need for collaborative working between NHS professionals and care home staff to achieve sustainable changes to working practices that focus on the health and well-being of residents in care homes 
(Baylis \& Perks-Baker, 2017, Smith et al, 2018). These positive findings address some of the cultural challenges identified in our study and support a progressively focused policy discourse including rehabilitation, re-ablement and person-centred care for nursing home residents (NHS England 2016).

Due to the complexities of dementia, participants described the need for specialist measurement tools to demonstrate the impact of the role. This included assessing quality of life through observing residents' behaviour as well as gaining patient, staff, and family feedback. These types of specialist measures have been used as primary outcomes within a small number of studies reviewed (Cruz et al., 2011; Marques et al., 2013), although Wikstrom-Grotell \& Eriksson (2012) argued that physiotherapy research should focus more on humanistic aspects including the emotional, sociocultural and existential components of movement. More publications have suggested that despite health and care professionals preferences for humanistic measures, NHS performance measures have been used to assess the impact of interventions on the care home population (Baylis \& Perks-Baker, 2017).

\section{Strengths and limitations}

This study's strength lies in allowing the voices to be heard through qualitative interviewing of allied health professional staff referring to and delivering physiotherapy, sometimes in roles that span this semantic division, to people with dementia in nursing homes. . The context is a need for referrers involved with people with dementia to understand physiotherapists' role (Dementia Action Alliance, 2015).

The limitations include a small sample size limited to a single metropolitan borough, and failing to attract GP and nursing home staff participants, despite adhering to recommended practices to maximize recruitment including multiple communication approaches with nursing home managers (Garcia et al., 2013); flexibility in study procedures (Maas et al., 2002) and involving gatekeepers in the study design (Luff et al., 2011). We did not offer participants the opportunity to check transcriptions, or our interpretation of findings. These limitations do not detract from the potential transferability of the perception of allied health professionals of physiotherapy for people with dementia in nursing homes in other geographical settings. However, implications for practice exist; if allied health professionals working as referrers to physiotherapy within-borough domiciliary-based teams found the role unclear, then it is likely that referrers who are further removed may find it less clear. We have been unable to ascertain that perception in this study. There was potential for social desirability bias to occur within participants' responses and for the researcher as a physiotherapist - to favour positive over negative participant data with regard to physiotherapists and emphasise negative aspects of the nursing home setting. We mitigated against this by using a team approach to coding and 
analysis, and the use of reflection, but, in the absence of resource to fully implement member checks and address their potential influence on interpretation in this study (Birt et al., 2016) we reduce rigour.

\section{Implications for practice}

We uncovered descriptions of collaborative working for the benefit of the patient and broad concern for patients, that are consistent with recent definitions of physiotherapy including: health and wellbeing promotion activities emphasising the importance of physical activity; preventing movement impairments and activity limitations; providing interventions to support movement, function and quality of life; and making modifications to enable participation in society (WCPT, 2015). However, we also noted practice that appeared to belie a narrow focus on physical aspects of movement and not broader existential aspects (Wikstrom-Grotell \& Eriksson, 2012), highlighting where physiotherapy providers may be diverging from the WCPT (2015) and CSP's (2013) holistic physiotherapy definition. This raises ethical issues including potential discrimination in access to services for people with dementia in nursing homes particularly as, in this study, some gatekeepers to these services proved difficult to engage. There was a perception of marginalisation of providers of the services and some tendency toward critique of 'others' for areas of deficit. This leads us to suggest two strands of implication for practice, one pragmatic, the other focused on underpinning belief systems. Pragmatically, we suggest that attention is given to the provision of education to physiotherapists to enhance their skills, abilities and confidence when managing complexities associated with working in nursing homes with residents with dementia. Those noting failures in healthcare education regarding dementia across Europe (Hvalič-Touzery 2018) and the USA (Adler et al 2015), suggest that 'investment in inter-professional evidence-based education is required if we are to respond effectively and compassionately to the needs of people living with dementia and their families' (Hvalič-Touzery 2018:161). Our research highlighted a need for dialogue to occur between referrers and providers of physiotherapy around the role. We suggest that this dialogue should include views of people with dementia and their families, and take place at a strategic level within and across organisations that provide care to residents with dementia to establish the shared goals, values and common norms considered fundamental to collaboration (Collins 2016), and aid the development of meaningful outcomes, thereby reducing uncertainty around role and service delivery (Coulter, 2013). This dialogue may uncover issues such as our small study has, of varying attitudes toward outcomes a physiotherapist might pursue with a person with dementia in a nursing home and therefore their role. Whilst national and international definitions of the role take a holistic view to the notions of mobility and function, without specific guidelines for this population, these remain open to interpretation. 


\section{Conclusion}

In exploring perceptions of the role of domiciliary physiotherapists who treat residents with dementia in nursing homes from the viewpoint of the main referrers to, and the providers of domiciliary physiotherapy, we found a recognition that physiotherapists, if effectively utilised, could improve outcomes for people with dementia in nursing homes. However, a number of significant and complex challenges were identified, rooted in uncertainty about role and differing interpretations of professional definitions of physiotherapy. Education of physiotherapists and support for interdisciplinary team and organisational working could enhance physiotherapists' role working with people with dementia in nursing homes. Further research is recommended to gather views from a wider geographical area, from GPs and nursing home staff, residents and their families, and from those involved in commissioning service provision. Additional research is also required to facilitate the development of professional guidance for physiotherapists working with people with dementia. We propose that this research could explore interpretations of the meanings of mobility, function and quality of life in nursing home residents with dementia. 


\section{References}

Alzheimer's Disease International (2013, December, no date) The Global Impact of Dementia 2013-2050. Retrieved from https://www.alz.co.uk/research/GlobalImpactDementia2013.pdf Alzheimer's Disease International.

Alzheimer's Society (2014) Dementia UK: Second Edition - overview.. Retrieved from http://www.alzheimers.org.uk/dementiauk

Adler, G. Lawrence, B. M., Ounpraseuth, S. T., \& Asghar-Ali, A. A. (2015) A Survey on Dementia Training Needs Among Staff at Community-Based Outpatient Clinics, Educational Gerontology, 41, 903-915.

doi: $\underline{10.1080 / 03601277.2015 .1071549}$

Baert, V., Gorus, E., Guldemont, N., De Coster, S. \& Bautmans, I. (2015). Physiotherapists' perceived motivators and barriers for organizing physical activity for older long-term care facility residents. Journal of the American Medical Directors Association, 16, 371-379. doi.org/10.1111/j.1365-2702.2009.02990.x

Barrett, E., \& Burns, A. (2014) Dementia Revealed. What Primary Care Needs to Know. Retrieved from http://www.england.nhs.uk/wp-content/uploads/2014/09/dementia-revealed-toolkit.pdf

Baylis, A. and Perks-Baker, S., (2017) Enhanced health in care homes. Learning from experiences so far. Retrieved from: https://www.kingsfund.org.uk/sites/default/files/2017-

11/Enhanced_health_care_homes_Kings_Fund_December_2017.pdf

Braun, V., \& Clarke, V. (2006). Using thematic analysis in psychology. Qualitative Research in Psychology, 3, 77 101. doi.org/10.1191/1478088706qp063oa

Bryman, A. (2012) Social Research Methods (4th ed.). Oxford: Oxford University Press.

Buddingh, S., Liang, J., Allen, J., Koziak, A., Buckingham, J. \& Beaupre, L., A. (2013). Rehabilitation for Long-term Care Residents Following Hip Fracture: A Survey of Reported Rehabilitation Practices and Perceived Barriers to Delivery of Care. Journal of Geriatric Physical Therapy, 36, 39-46. doi: 10.1519/JPT.0b013e3182569b4f 
Bunn, F., Burn, A-M., Robinson, L., Poole, M., Rait, G., Brayne, C., Schoeman, J., Norton S., \& Goodman, C. (2017) Healthcare organisation and delivery for people with dementia and comorbidity: a qualitative study exploring the views of patients, carers and professionals. BMJ Open, 7:e013067. doi:10.1136/bmjopen-2016-013067

Burn, D., May, S. \& Edwards, L. (2014). General Practitioners' Views About an Orthopaedic Clinical Assessment Service. Physiotherapy Research International, 19, 176-185. doi.org/10.1002/pri.1581

Burton, E., Cavalheri, V., Adams, R., Browne, C. O., Bovery-Spencer, P., Fenton, A. M., Campbell, B. W. \& Hill, K. D. (2015). Effectiveness of exercise programs to reduce falls in older people with dementia living in the community: a systematic review and meta-analysis, Clinical Interventions in Aging, 10, 421-434. doi.org/10.2147/CIA.S71691

Care Quality Commission (2014, October 16) State of Care 2013/14. Retrieved from https://www.cqc.org.uk/news/stories/what $\% \mathrm{E} 2 \% 80 \% 99$ s-state-care-england

Chartered Society of Physiotherapy (2011) Physiotherapy works: dementia care. Retrieved from http://www.csp.org.uk/publications/physiotherapy-works-dementia-care

Chartered Society of Physiotherapy, (2013) The Physiotherapy Framework (condensed version). Retrieved from: https://www.csp.org.uk/system/files/documents/2018-06/csp_physiotherapy_framework_condensed_2013.pdf

Coulter, A., Roberts, A., \& Dixon, A. (2013, October No Date Published) Delivering better services for people with long-term conditions. Retrieved from https://www.kingsfund.org.uk/sites/default/files/field/field_publication_file/delivering-better-services-for-peoplewith-long-term-conditions.pdf

Collins B. (2016, October 11) Reuniting Care. Retrieved from https://www.kingsfund.org.uk/blog/2016/10/reuniting$\underline{\text { care }}$

Creswell, J. (2013) Qualitative Inquiry and Research Design. Choosing Among Five Approaches (3rd ed.). United States of America: SAGE. 
Cruz, J., Marques, A., Barbosa, A. L., Figueiredo, D., \& Sousa, L. (2011) Effects of a motor and multisensory-based approach on residents with moderate-to-severe dementia. American Journal of Alzheimer's Disease and Other Dementias, 26 282-289. doi: 10.1177/1533317511411177

Dalley, J., and Sim, J. (2001) Nurses' perceptions of physiotherapists as rehabilitation team members, Clinical Rehabilitation, 15, 380-389. doi: 10.1191/026921501678310180

Dementia Action Alliance (2015) Chartered Society of Physiotherapy Action Plan. Retrieved from http://www.dementiaaction.org.uk/members_and_action_plans/53-chartered_society_of_physiotherapy

Department of Health (2011) Living well with Dementia: A national dementia strategy. Retrieved from: https://assets.publishing.service.gov.uk/government/uploads/system/uploads/attachment_data/file/168220/dh_094051. pdf

Department of Health (2016) NHS Outcomes Framework: at-a-glance. List of outcomes and indicators in the NHS Outcomes Framework for 2016-17. Retrieved from:

https://assets.publishing.service.gov.uk/government/uploads/system/uploads/attachment data/file/513157/NHSOF at a_glance.pdf

Finlay, L. \& Gough, B. (2003) Reflexivity. A Practical Guide for Researchers in Health and Social Sciences. Oxford: Blackwell.

Forbes, D., Forbes, S.C., Blake, C.M., Thiessen, E.J., \& Forbes, S. (2015) Exercise programs for people with dementia (Review). Cochrane Database of Systematic Reviews, 4, No.: CD006489. doi: 10.1002/14651858.CD006489.pub4

Fossey, E., Harvey, C., McDermott, F., \& Davidson, L. (2002) Understanding and evaluating qualitative research, Australian and New Zealand Journal of Psychiatry, 36, 717-732. doi: 10.1046/j.1440-1614.2002.01100.x

Garcia, C., Kelley, C. M. \& Dyck, M. J. (2013) Nursing home recruitment: Trials, tribulations, and successes, Applied Nursing Research, 26, 136-138. doi: 10.1016/j.apnr.2013.01.001 
Goodman C, Davies SL, Gordon AL, Dening T, Gage H, Meyer J, et al. Optimal NHS service delivery to care homes: a realist evaluation of the features and mechanisms that support effective working for the continuing care of older people in residential settings. Health Serv Deliv Res 2017;5(29). doi: https://doi.org/10.3310/hsdr05290

Goodwin, K. (2014) An exploratory study into student midwives understanding of the role of the physiotherapist, British Journal of Midwifery, 22, 362-368. doi:10.12968/bjom.2014.22.5.362

Green, J.G., \& Thorogood, N. (2014) Qualitative Methods for Health Research. (3rd edn). London: Sage.

Greenwood, C., Cranston, A., \& Garrib, A. (2014) Care Home Needs Assessment in Wandsworth Retrieved from https://www.datawand.info/wp-content/uploads/2018/07/Care Homes_NA Final_For_publication_April2014.pdf

Hall, A., Goodwin, V., Lang, I., \& Endacott, R. (2016) Physiotherapeutic interventions for people with dementia and hip fracture - a scoping review of the literature.Physiotherapy,102, e187. doi: 10.1016/j.physio.2017.01.001.

Hall, A.J., Watkins, R., Lang, I.A., Endacott, R. \& Goodwin, V.A. (2017) The experiences of physiotherapists treating people with dementia who fracture their hip. BMC Geriatrics, 17, 91. doi.org/10.1186/s12877-017-0474-8.

Hall, A.J., Burrows, L., Lang, I.A., Endacott, R., \& Goodwin, V.A. (2018) Are physiotherapists employing personcentred care for people with dementia? An exploratory qualitative study examining the experiences of people with dementia and their carers. BMC Geriatrics, 18, 63. doi.org/10.1186/s12877-018-0756-9

Hammond, R. (2016) The construction of professional identity by physiotherapists: A qualitative study, Physiotherapy, 102, 71-77. doi: 10.1016/j.physio.2015.04.002

Hvalič-Touzery, S., Skela-Savič, B., Macrae, R., Jack-Waugh, A., Tolson, D., Hellström, A., de Abreu, W., \& $\underline{\text { Pesjak, }}$

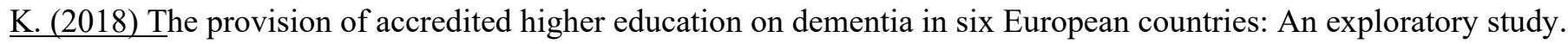
Nurse Education Today,60, 161-169. doi: 10.1016/j.nedt.2017.10.010.

Keus, S., Munneke, M., Graziano, M., Paltamaa, J., Pelosin, E., Domingos, J., Brühlmann, S., Ramaswamy, B., Prins, J. and Struiksma, C. (2014) European physiotherapy guideline for Parkinson's disease. Retrieved from https://www.parkinsonnet.nl/media/15336569/addendum_evidence_engelstalig_kngf richtlijn_ziekte_van_parkins 
Leemrijse, C. J., de Boer, M. E., van den Ende, C. H., Ribbe, M. W. and Dekker, J. (2007) Factors associated with physiotherapy provision in a population of elderly nursing home residents; a cross sectional study, BMC Geriatrics, 7, 7. doi: $\underline{10.1186 / 1471-2318-7-7}$

Lefmann, S., Sheppard, L. (2014) Perceptions of emergency department staff of the role of physiotherapists in the system: a qualitative investigation, Physiotherapy, 100, 86-91. doi: http://dx.doi.org/10.1016/j.physio.2013.08.004

Luff, R., Ferreira, Z. \& Meyer, J. (2011) Care homes. National Institute for Health Research School for Social Care Research. Retrieved from http://eprints.lse.ac.uk/41191/1/SSCR_Methods_Review_8_web.pdf

Lyall, J. (2008) On home ground. Frontline, 14, no page number. Retrieved from http://www.csp.org.uk/frontline/article/home-ground

NHS England (2019) Quick guide: allied health professionals enhancing health for people in care homes Retrieved from: https://www.england.nhs.uk/wp-content/uploads/2019/07/ahp-quick-guide-ahp-care-home.pdf

Maas, M. L., Kelley, L. S., Park, M. and Specht, J. P. (2002) Issues in conducting research in nursing homes, Western Journal of Nursing Research, 24, 373-389. doi:10.1177/01945902024004006

Marks D., \& Yardley, L. (2004) Research methods for clinical and health psychology. London: Sage.

Marques, A., Cruz, J., Barbosa, A., Figueiredo, D., \& Sousa, L. X. (2013) Motor and multisensory care-based approach in dementia: long-term effects of a pilot study, American Journal of Alzheimer's Disease and Other Dementias, 28, 24-34. doi: $\underline{10.1177 / 1533317512466691}$

McArthur, C., Gibbs, J., Papaioannou, A., Hirdes, J., Milligan, J., Berg, K., \& Giangregorio, L. (2015) Scoping review of physical rehabilitation interventions in long-term care: protocol for tools, models of delivery, outcomes and quality indicators, BMJ Open, 5, e007528-2014-007528. doi: 10.1136/bmjopen-2014-007528

National Institute for Clinical Excellence (NICE) (2013) Dementia: Independence and wellbeing Retrieved from: https://www.nice.org.uk/guidance/qs30 
Owen, T., and Meyers, J., (2012) My home life: Promoting quality of life in care homes Retrieved from: https://www.jrf.org.uk/report/my-home-life-promoting-quality-life-care-homes

O’Dea, G., Kerrison, S. H., \& Pollock, M. A. (2000) Access to health care in nursing homes: a survey in one English Health Authority, Health \& Social Care in the Community, 8 180-185. doi.org/10.1046/j.1365-2524.2000.00238.x

Parkes, S., \& Ali, A. (2013) GPs' perceptions of physiotherapy services, British Journal of Healthcare Management, 19, 497-503. doi: $10.12968 /$ bjhc.2013.19.10.497

Prince, M., Wimo, A., Guerchet, M., Ali, G.C., Wu, Y.-T., \& Prina, M. (2015) World Alzheimer Report 2015. The Global Impact of Dementia. An analysis of prevalence, incidence, costs and trends. Alzheimer's Disease International. Retrieved from https://www.alz.co.uk/research/world-report-2015

Robson, C. (2002) Real World Research (2nd edn.). Oxford: Blackwell.

Sackley, C., Hoppitt, T., Cardoso, K., \& Levin, S. (2009) The availability and use of allied health care in care homes in the Midlands, UK, International Journal of Therapy and Rehabilitation, 16 218-224.

doi.org/10.12968/ijtr.2009.16.4.41195

Santos, K. (2015) Advice line: Katherine Santos provides insight into working in care homes. Frontline, 21, no page number. Retrieved from http://www.csp.org.uk/frontline/article/advice-line-katherine-santos-provides-insightworking-care-homes

$\underline{\text { Scottish Intercollegiate Guidelines Network (SIGN) (2006) Management of patients with dementi; } \text { A national clinical }}$ guideline Retrieved from: http://umh1946.edu.umh.es/wp-content/uploads/sites/172/2015/04/Management-of-patientswith-dementia-NHS.pdf

Smith, S., \& Roberts, P. (2005) An investigation of occupational therapy and physiotherapy roles in a community setting, International Journal of Therapy and Rehabilitation, 12 21-29. doi.org/10.12968/ijtr.2005.12.1.17358

$\underline{\text { Smith, R., Wood, J., Jones, F., Turner, S., and Hurley, M. (2018) A qualitative study exploring therapists' experiences }}$ of implementing a complex intervention promoting meaningful activity for residents in care homes, Clinical 
Staples, W. H., \& Killian, C. B. (2012a) Education affects attitudes of physical therapy providers toward people with dementia, Educational Gerontology, 38 350-361. doi: https://doi.org/10.1080/03601277.2010.544605

Staples, W. H. and Killian, C. B. (2012b) Development of an instrument to measure attitudes of physical therapy providers working with people with dementia, American Journal of Alzheimer's Disease and Other Dementias, 27 331-338. doi.org/10.1177/1533317512452041

Stewart, S., Macha, R., Hebblethwaite, A., \& Hames, A. (2009) Residential carers' knowledge and attitudes towards physiotherapy interventions for adults with learning disabilities, British Journal of Learning Disabilities, 37 232-238. doi.org/10.1111/j.1468-3156.2009.00554.x

Waldron, M., Kernohan, W. G., Hasson, F., Foster, S., Cochrane, B., \& Payne, C. (2011) Allied health professionals' views on palliative care for people with advanced Parkinson's disease, International Journal of Therapy and Rehabilitation, 18 48-58. doi.org/10.12968/ijtr.2011.18.1.48

While, A., Forbes, A., Ullman, R., \& Mathes, L. (2009) The role of specialist and general nurses working with people with multiple sclerosis, Journal of Clinical Nursing, 18 2635-2648. doi: 10.1111/j.1365-2702.2008.02459.x.

Wikström-Grotell, C., \& Eriksson, K. (2012) Movement as a basic concept in physiotherapy-A human science approach, Physiotherapy Theory and Practice, 28 428-438. doi: 10.3109/09593985.2012.692582

Williams, J., Kaasalainen, S., Hadjistavropoulos, T., Scudds, R., Thorpe, L., Neville, S., Tremeer, J., \& Andersen, D. (2011) A qualitative investigation of injurious falls in long-term care: perspectives of staff members, Disability and Rehabilitation, 33 423-432. doi: 10.3109/09638288.2010.498555

World Confederation of Physical Therapy. (2015) Policy statement: Description of physival therapy Retrieved from: https://www.wcpt.org/policy/ps-descriptionPT

Yardley, L. (2008) Demonstrating validity in qualitative psychology, in Smith, J.A. Qualitative psychology: A practical guide to methods 2nd edn. London: Sage, pp 235-251.

You, L., Sadler, G., Majumdar, S., Burnett, D., \& Evans, C. (2012) Physiotherapists' perceptions of their role in the rehabilitation management of individuals with obesity, Physiotherapy Canada, 64 168-175. doi: 10.3138/ptc.2011-01. 
- Table 1: Inclusion criteria and expressions of interest and participation

\begin{tabular}{|l|l}
\hline Inclusion Criteria & Exclusion Criteria
\end{tabular}

- Belong to a main referrer group to domiciliary physiotherapy for people with dementia in nursing homes in one locality (English

Metropolitan borough), comprising health care or medical professionals from:

- Twelve nursing homes

- Nine general practices

- One generic domiciliary therapy team*

- Two specialist domiciliary therapy teams*

- One acute hospital therapy team

- One rehabilitation hospital therapy team

- Belong to a provider team for domiciliary physiotherapy for people with dementia in nursing homes in one English Metropolitan borough, comprising health care professionals from:

- One domiciliary therapy team*

- Two specialist domiciliary therapy teams*

*staff from these teams could be both providers of and referrers to the service due to rotational staff activities

- Capacity to give consent
- Belongs to a group who can refer but are not the main referrers in the locality

- A domiciliary physiotherapy team member whose core workload does not include nursing home residents in the locality 
Table 2 Participant characteristics

$\begin{array}{llll}\text { Participant ID } & \text { Profession } & \text { Length of clinical } & \text { Referrer to or } \\ & \text { experience } & \text { provider of } \\ & & \text { physiotherapy }\end{array}$

\begin{tabular}{lllll}
\hline Participant 1 & Occupational & Generic domiciliary & 6 -10years & Referrer \\
& Therapist & & \\
\hline Participant 2 & Speech and Language & Specialist domiciliary & $>10$ years & Referrer \\
& Therapist & 2 & & \\
\hline Participant 3 & Occupational & Generic domiciliary & $>10$ years & Referrer \\
& Therapist & & & \\
\hline Participant 4 & Physiotherapist & Specialist & $>10$ years & Referrer and provider \\
& & domiciliary & &
\end{tabular}

\begin{tabular}{|c|c|c|c|c|}
\hline Participant 5 & Physiotherapist & $\begin{array}{l}\text { Specialist domiciliary } \\
1\end{array}$ & $6-10$ years & Referrer and Provider \\
\hline Participant 6 & $\begin{array}{l}\text { Speech and Language } \\
\text { Therapist }\end{array}$ & $\begin{array}{l}\text { Rehabilitation } \\
\text { hospital therapy team }\end{array}$ & $>10$ years & Referrer \\
\hline Participant 7 & Physiotherapist & Generic domiciliary & 6-10years & Provider \\
\hline Participant 8 & Physiotherapist & $\begin{array}{l}\text { Rehabilitation } \\
\text { hospital therapy team }\end{array}$ & $>10$ years & Referrer \\
\hline Participant 9 & Physiotherapist & Generic domiciliary & $6-10$ years & Provider \\
\hline Participant 10 & Physiotherapist & $\begin{array}{l}\text { Specialist domiciliary } \\
1\end{array}$ & $>10$ years & Referrer and provider \\
\hline No participants & $\begin{array}{l}\text { General practitioner, } \\
\text { acute hospital therapy } \\
\text { and nursing home } \\
\text { staff }\end{array}$ & - & - & Referrers \\
\hline
\end{tabular}


Figure 1

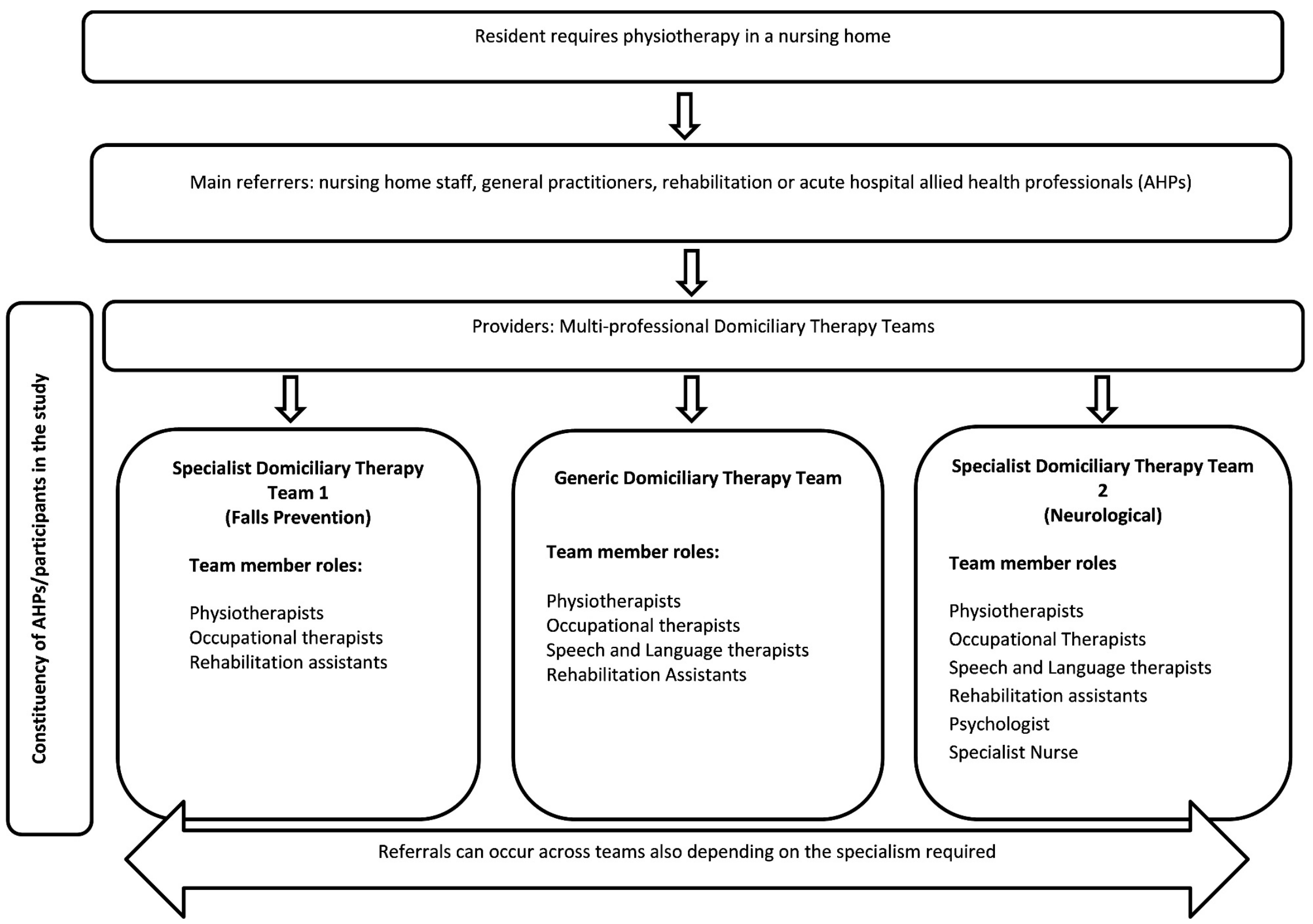


Figure 2

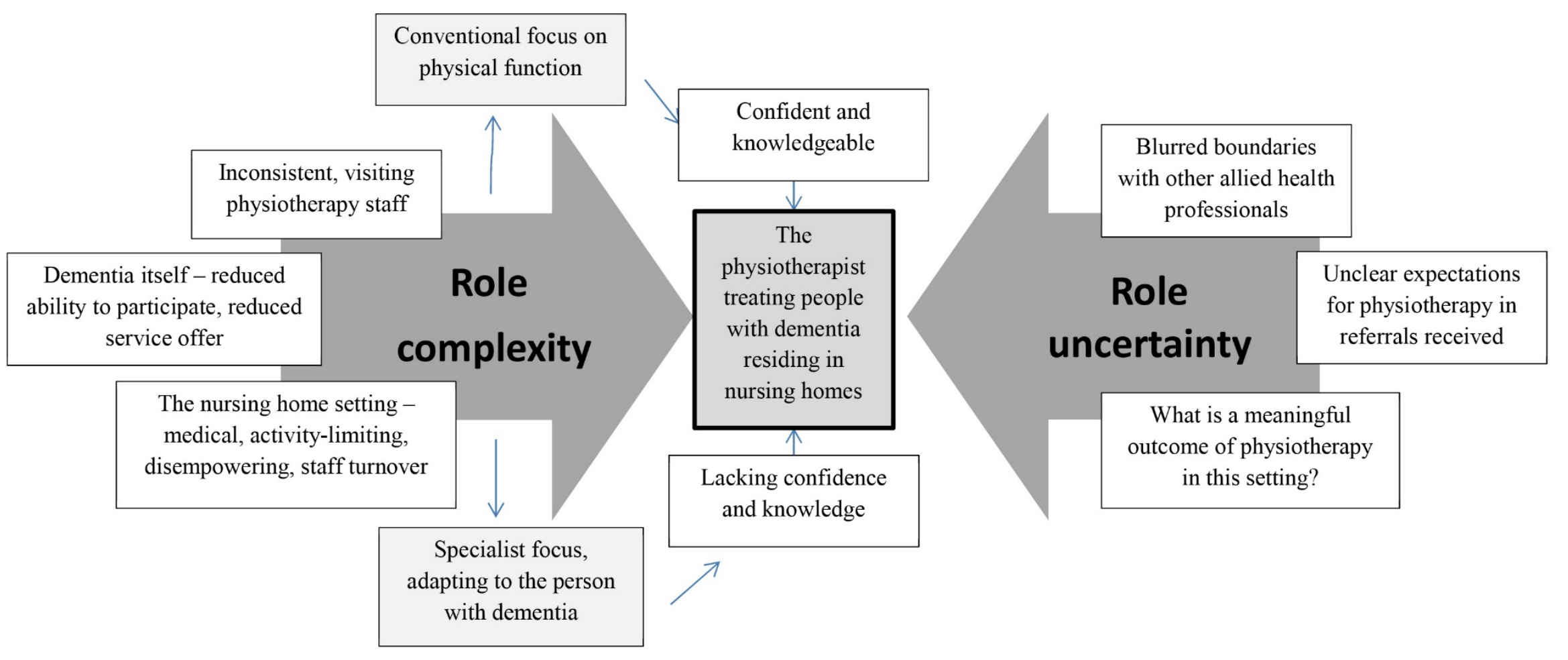

